\title{
Outcome of Fixed Dose Combination of Tenofovir, Lamivudine and Dolutegravir in Rural HIV Care Facility in Nigeria
}

\author{
Ogbuagu Chukwuanugo Nkemakonam¹, Ogbuagu Ekenechukwu Nkiloka ${ }^{2}$, \\ Okoh Emeka Emmanuel ${ }^{3}$, Olli Ugochinyere $\mathrm{T}^{3}$, Okereke Uzoma Chidi ${ }^{3}$, \\ Emelumadu Obiageli Fidelia ${ }^{3}$, Modebe Ifeoma Ann ${ }^{3}$, Eleje George Uchenna ${ }^{4}$, \\ Kazibwe Sophia ${ }^{5}$
}

\author{
${ }^{1}$ Department of Public Health, School of Allied Health Sciences, Kampala International University Western \\ Campus Ishaka, Uganda. \\ ${ }^{2}$ Family Medicine Department, GOPD, NnamdiAzikiwe University Teaching Hospital Nnewi Anambra State, \\ Nigeria. \\ ${ }^{3}$ Comprehensive Health Centre, Nnamdi Azikiwe University Teaching Hospital Neni, Anambra State, Nigeria. \\ ${ }^{4}$ Effective Care Research Unit, Department of Obstetrics and Gynecology, Faculty of Medicine, College of \\ Health Sciences, Nnamdi Azikiwe University, Awka, Nigeria. \\ ${ }^{5}$ Office of the Deputy Vice Chancellor Academic Affairs, Kampala International University Uganda.
}

Corresponding Author: Chukwuanugo N Ogbuagu

\begin{abstract}
Background: Antiretroviral therapy (ART) has significantly increased the lifespan of people living with HIV. Currently, fixed dosed combination therapy (Tenofovir, Lamivudine, and Dolutegravir) is being introduced in most countries in the Sub- Saharan Africa. There is need for a clinical and immunological assessment of HIV patients transitioned to this new therapy over a period of 2 years.

Objectives: To determine the proportion of patients whose viral load was suppressed to $<20$ copies/ml following two years therapy with Dolutegravir-based fixed-dose combination therapy.

Methods: This retrospective cohort study was carried out in a Comprehensive Healthcare Centre (CHC), a facility affiliated with Nnamdi Azikiwe University Teaching Hospital Nigeria. The primary outcome measure was the proportion of patients whose viral load was suppressed to $<20$ copies $/ \mathrm{ml}$. The plasma viral load (HIV-RNA) assay was done using real time PCR and CD4 ${ }^{+}$T- lymphocyte $\left(\mathrm{CD}^{+}\right)$counts were estimated using Flow Cytometry. The exclusion criteria were patients who has invalid data base and patients with comorbidities associated with HIV.

Results: A total of 537 HIV1 sero-positive patients were enrolled for ART care over a period of 2 years (2017-2018). Females in the age group (41-50 years) constituted the bulk (36.9\%) of the patients whilst the least (5.3\%) were males in the age group (8 to 30 years). The mean CD4 count of patients was 847.35 cells $/ \mathrm{mm}^{3}$. More females $(45.9 \%)$ had CD4 $4^{+}$counts over 500 cells $/ \mathrm{mm}^{3}$ whilst the percentage of males with $\mathrm{CD}^{+}$cell counts over 500 cells $/ \mathrm{mm}^{3}$ was $43.8 \%$. Majority, 405 constituting $75.4 \%$ of the patients have suppressed viral load $(<20$ copies $/ \mathrm{ml})$ signifying that the centre is achieving success with respect to service delivery and ART. Patients with unsuppressed viral loads were more among Females with CD4+ counts in the range of 200-499 cells $/ \mathrm{mm}^{3}$ and this may be as a result of other associated factors which will be elucidated in future studies.

Conclusion: Dolutegravir-based fixed-dose combination therapy suppressed viral load to $<20$ copies $/ \mathrm{ml}$ in more than $75 \%$ of patients receiving the therapy. Enhanced adherence and effective doctor-patient relationship could be associated with the viral suppression observed in this study.
\end{abstract}

Key Words: Immunology, virology, HIV Outcome, Dolutegravir-based combination therapy, anti retroviral therapy. 


\section{INTRODUCTION}

HIV/AIDs pandemic has claimed more than 35million lives so far [1,2]. Based on a study in 2019, there were approximately 38million people living with HIV with 1.7million people becoming newly infected in the same year.[3-6]. The introduction of potent combinations of antiretroviral drugs into the HIV programmes across the world has dramatically altered the natural progression of HIV infection and significantly improved HIV clients' quality of life [7]. The use of the fixed dose combination of Tenofovir, Lamivudine and Dolutegravir has been recommended and supported by President's Emergency Plan for AIDs Relief (PEPFAR) for use priority countries.[8]. Forecast suggests that approximately 15million people will be taking TDF/3TC/DTG by 2021, progressively replacing first line TDF/3TC/EFV600 recommended by WHO in 2016[9,10]

However, the introduction of second generation HIV-1 integrase strand transfer inhibitor (INSTI) Dolutegravir (DTG) has had a major impact on the treatment of HIVinfection, demonstrating both efficacy [812] and a high barrier to resistance[13-15]. The most important factor affecting the clinical efficacy of antiretroviral drugs is the intrinsic antiviral activity, which is a function of both the IC50 and the doseresponse curve slope $(16,17)$; together with genetic barriers to resistance, but there is minimal resistance to DTG[18,19]. Furthermore, the integrase inhibitor Dolutegravir has shown improved safety profile compared with Efavirenz in randomised studies. An observational study in Botswana has shown an increased risk of neural tube defects when Dolutegravir is used early in pregnancy [20]. However, there is a dearth of studies to support this finding. Using the records of patients accessing care in our facility, we were able to study the clinical responses of patients who have been on Dolutegravir based fixed dose combination as the current first line regimen for HIV. The aim of this study was to determine the proportion of HIV positive patients whose viral load was suppressed to $<20$ copies/ml following two years therapy with Dolutegravir-based fixed-dose combination therapy.

\section{METHOD}

A retrospective cohort study involving all the adult HIV/AIDS cohorts in Nnamdi Azikiwe University Teaching Hospital (NAUTH) Comprehensive Health Center (CHC) Neni, Anambra State, Nigeria, over a two-year period ( $1^{\text {st }}$ January, 2017 to $31^{\text {st }}$ December, 2018) was conducted. NAUTH CHC Neni, Anambra State, Nigeria is a tertiary healthcare facility located in the Southeastern Nigeria with a geographic coordinates of $6.0809^{\circ} \mathrm{N}$, $7.0015^{\circ} \mathrm{E}$. The facility offers a comprehensive HIV care treatment and management for all patients who choose the facility to assess care. The total data of patients attending the HIV-Care Clinic at the CHC was collated from Lafiya Management Information System (LAMIS software), the central medical records data collation platform for the Family Health International anchored HIV care treatment services in Nigeria.

\section{INCLUSION CRITERIA}

All patients aged 18 years and above who registered and accessing HIV care and treatment from the facility

\section{EXCLUSION CRITERIA}

All patients with other comorbidities associated with HIV such as Cancers, and patients with incomplete registration with the facilities and or defaulted were excluded.

\section{SAMPLE SIZE CALCULATION}

Convenient sampling technique was used in selecting all the patients' data enrolled the study.

SPSS version 21, Chi square and frequency tables were used in result analysis. Medical records summation of the two years study attendance showed a total 
of 537 patients were registered within the study period and assessing care from the facility. The plasma viral load (HIV-RNA) assay was done using real time PCR and $\mathrm{CD}^{+} \mathrm{T}$ - lymphocyte $\left(\mathrm{CD}^{+}\right)$counts were estimated using Flow Cytometry. Ethical clearance was gotten from NAUTH, Nnewi, Nigeria for the study.

\section{RESULT}

The data of 537 patients accessing ART for a period of 2 years (Jan 2017 to Dec 2019) were retrieved. This included demographical characteristics and the latest viral load and CD4+ cell counts of clients. There were 171 males and 366 females with a male-female ratio of $1: 4.7$. The overall minimum age was 8 years and maximum age of 85years with a mean of $45.69+/-$ 11.29 years. The mean age of males was $49.12+/-11.75$ years, and that of females was $44.08+/-10.71$ years. Majority of the clients were between 41-50 years totaling $193(35.9 \%)$ of the patients, while 185 (21.8\%) were above 50 years and 42 (7.8\%) were between 8 and 30 years.

Furthermore, the immunological outcome (latest CD4 cell counts) of HIV patients in the facility were retrieved and analyzed. Overall, 243 out of 537(45.3\%) have CD4+ count over 500cells $/ \mathrm{mm}^{3}$ and the same was obtained among those with CD4 counts between 200 to 499cells/mm3, with 51out of 537(9.5\%) having CD4 less than 200 cells/mm3.

Table 1: Demographic profile of the patients (Jan 2017 and Dec 2019).

\begin{tabular}{|l|l|l|l|}
\hline GENDER/AGE & MALE & FEMALE & OVERALL \\
\hline GENDER & $171(537)$ & $366(537)$ & 537 \\
& $31.8 \%$ & $68.2 \%$ & $100 \%$ \\
\hline AGE RANGE (YEARS) & & & \\
\hline $8-30$ & $9(171)$ & $33(366)$ & $42(537)$ \\
& $5.3 \%$ & $9.0 \%$ & $7.8 \%$ \\
\hline $31-40$ & $21(171)$ & $96(366)$ & $117(537)$ \\
& $12.3 \%$ & $26.2 \%$ & $21.8 \%$ \\
\hline $41-50$ & $58(171)$ & $135(366)$ & $193(537)$ \\
& $33.9 \%$ & 36.9 & $35.9 \%$ \\
\hline$>50$ & $83(171)$ & $102(366)$ & $185(537)$ \\
& $48.5 \%$ & $27.9 \%$ & $34.5 \%$ \\
\hline Mean Age(Years) & $49.12 \pm 11.75$ & $44.08 \pm 10.71$ & $45.69 \pm 11.29$ \\
Mean \pm SD & & & \\
\hline CD4+ COUNT (Cells/mm 3 ) & $1532.70 \pm 9772.70$ & $526.27 \pm 554.04$ & $847.35 \pm 5547.70$ \\
\hline
\end{tabular}

Data from 537 registered patients were reviewed, consisting of 171 (31.8\%) males and $366(68.2 \%)$ females. The overall minimum age was 8years and the maximum 85 years with a mean of $45.69 \pm 11.29$ years. A majority 193 of 537 (35.9\%) of all patients were between 41-50 years, 185 of 537 (21.8\%) between 315-40 years and only 42 of 534 (7.8\%) were between the age ranges of 8-30 years.

Table 2 The CD4 count of the patients presented between 2017 and 2018.
\begin{tabular}{|l|l|l|l|}
\hline CD4 COUNT (Cells/mm & MALE & FEMALE & OVERALL \\
\hline$<=200$ & $18(10.5)$ & $33(9.02)$ & $51(9.5)$ \\
\hline $201-499$ & $78(45.6)$ & $165(45.1)$ & $243(45.3)$ \\
\hline$>=500$ & $75(43.9)$ & $168(45.9)$ & $243(45.3)$ \\
\hline TOTAL & $171(100)$ & $366(100)$ & $537(100)$ \\
\hline
\end{tabular}

The CD4 count range with the highest occurrence is those within the range of 201499Cells $/ \mathrm{mm}^{3}$ and those greater than or equal to $500 \mathrm{n}=243$ (45.3\%) each. The female population being more in number than the male population. 


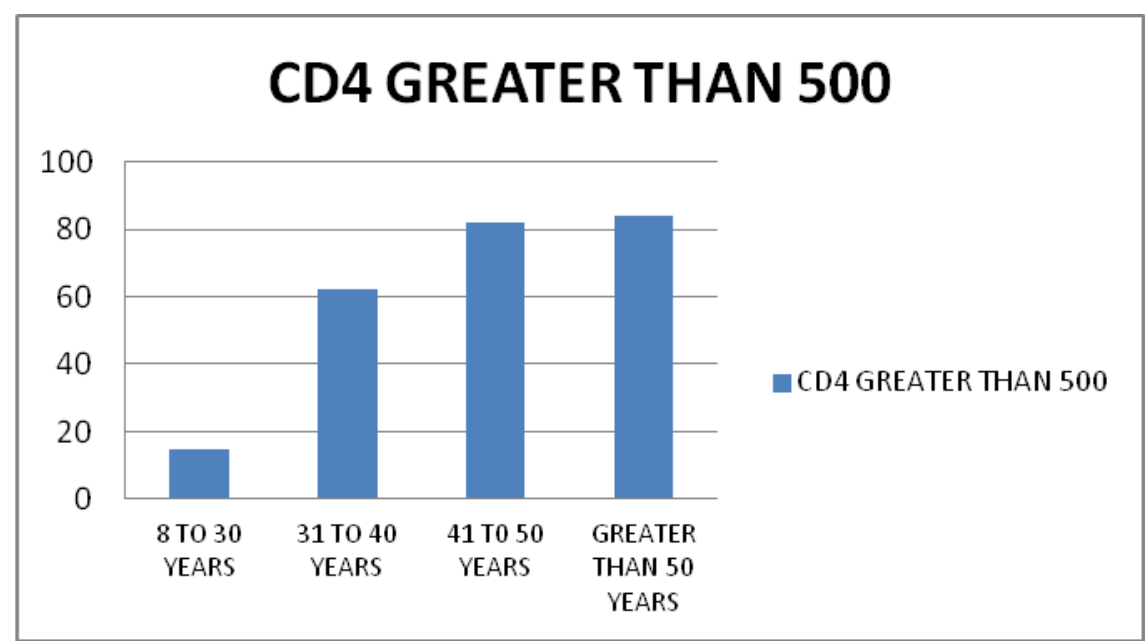

Figure 1: A total of 243 clients had CD4 greater than $500 \mathrm{cells} / \mathrm{mm} 3$. The highest proportion was among the age group greater than 50(84clients) and the least was age range of 8 to 30years (15)

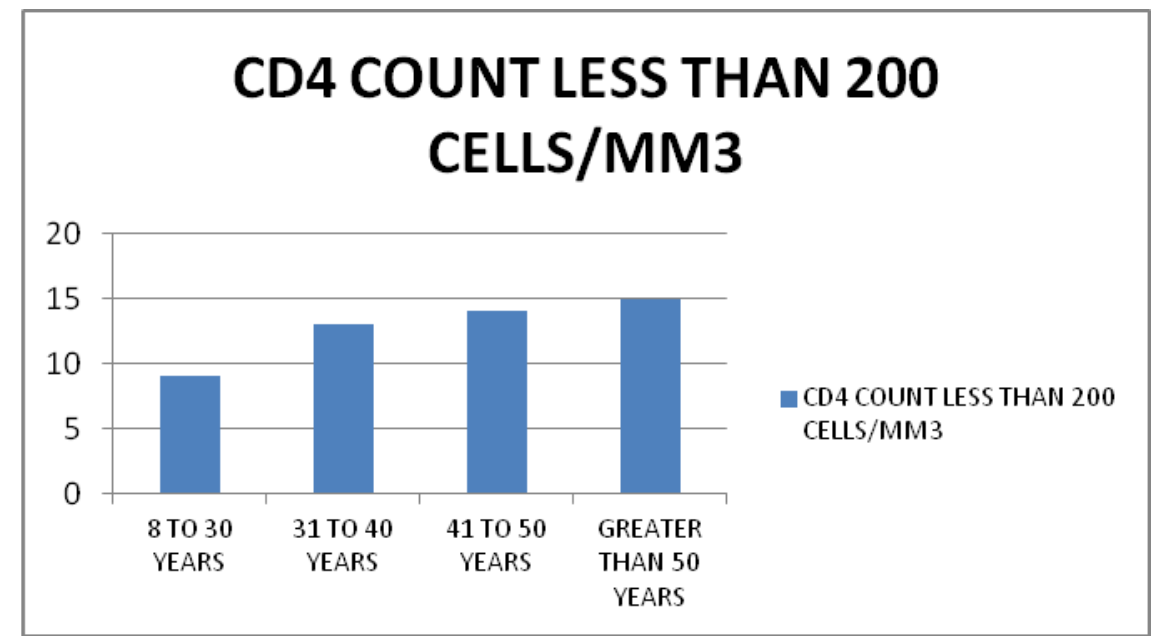

Figure 2: A total of 51 clients had CD4 less than 200cells/mm3. Patients in the age group of greater than 50 years had the highest (15) whereas the least was those in age group 5 to 30 years (9)

Table 3 CD4 counts distribution according to Viral Load and gender

\begin{tabular}{|c|c|c|c|c|c|}
\hline \multirow[b]{3}{*}{ CD4+ COUNT } & \multicolumn{4}{|c|}{ VIRAL LOAD (copies/ml) } & \multirow[b]{3}{*}{ OVERALL } \\
\hline & \multicolumn{2}{|c|}{$<20$ copies $/ \mathrm{ml}$} & \multicolumn{2}{|l|}{$>1000$} & \\
\hline & MALE(\%) & FEMALE(\%) & MALE(\%) & FEMALE(\%) & \\
\hline$<=200$ & $8(4.61)$ & $10(55.6)$ & $10(30.3)$ & $23(69.7)$ & $51(9.5)$ \\
\hline 201-499 & $58(33.92)$ & 111(65.7) & $20(27)$ & $54(73)$ & $243(45.3)$ \\
\hline$>=500$ & $68(39.77)$ & 150(68.8) & $7(28)$ & $18(72)$ & $243(45.3)$ \\
\hline OVERALL & $134(25)$ & 271(50.4) & $37(6.9)$ & $95(17.7)$ & $537(100)$ \\
\hline
\end{tabular}

405 patients have suppressed viral load (less than 20 copies $/ \mathrm{ml}$ ). 218 patients have CD4 count greater or equal to $500 \mathrm{cells} / \mathrm{mm}$. 132 patients have Viral Load greater than 1000copies/ml. 51 clients CD4 count less than 200cells/mm

Table 4 CD4 counts distribution according to age range and gender

\begin{tabular}{|c|c|c|c|c|}
\hline AGE RANGE (YRS) & CD4 COUNT (cells/mm³) & MALE & FEMALE & OVERALL \\
\hline \multirow{3}{*}{$8-30$} & $<=200$ & $3(33.3)$ & $6(18.2)$ & $9(21.4)$ \\
\hline & 201-499 & $2(22.2)$ & $16(48.5)$ & $18(42.9)$ \\
\hline & $>=500$ & $4(44.4)$ & 11(33.3) & $15(35.7)$ \\
\hline \multirow{3}{*}{$31-40$} & $<=200$ & $3(14.3)$ & $10(10.4)$ & $13(11.1)$ \\
\hline & $201-499$ & $6(28.6$ & $36(37.5)$ & $42(35.9)$ \\
\hline & $>=500$ & $12(57.1)$ & $50(52.1)$ & $62(53.0)$ \\
\hline \multirow{3}{*}{$41-50$} & $<=200$ & $7(50)$ & $7(5.2)$ & $14(7.3)$ \\
\hline & $201-499$ & $29(29.9)$ & $68(50.4)$ & $97(50.3)$ \\
\hline & $>=500$ & $22(26.8)$ & $60(44.4)$ & $82(42.5)$ \\
\hline \multirow{3}{*}{$>50$} & $<=200$ & $5(6.0)$ & $10(9.8)$ & $15(8.1)$ \\
\hline & 201-499 & $41(49.4)$ & $45(44.1)$ & $86(46.5)$ \\
\hline & $>=500$ & $37(44.4)$ & $47(46.1)$ & $84(42.5)$ \\
\hline
\end{tabular}




\section{DISCUSSION}

Since the inception of ART for HIV treatment in Nigeria, there has been a significant increment in the number of patients on ART, and improvement in their virological, immunological and clinical outcomes [21]. This significant improvement was noticed recently after the introduction of Tenofovir, Lamivudine and Dolutegravir fixed combination drug. Apparently, there seems to be a dearth of studies on the treatment outcome of HIV clients on this new ART in sub Saharan Africa. The ART regimen used in Nigeria has shown a good response in reducing HIV viral load but this cannot be said for the CD4 counts. This is so because there are other concomitant infections that significantly affect the CD4 count as well as logistic and technical challenges. The viral suppression rate among patients in this facility was $75.4 \%$ which is almost similar to a study conducted in Nepal where the viral suppression was between $78.95 \%$ and 92.86\% [22]. This viral load is higher than the global UNAID report at the end of 2019 where $59 \%$ of the people living with HIV had viral suppression [23]. This is a step in the right direction, which shall be monitored in future studies, with the aim of achieving the (90-90-90) targets. Furthermore, The viral failure rate $(24.6 \%)$ observed in this study was significantly higher than previous studies conducted in other countries like China 12.1\%[13], Nepal (9.94\%)[24-27] . These two countries used AZV/3TC/NVP, TDF/3TC/EFV which were initially used as the first line regimen before TDF/3TC/DTG combination was introduced in the study facility. There was no report of neural tube defects nor unfavourable birth outcomes among pregnant clients who took these medications during first trimester not because they were unaware of their pregnancy status but rather an indication of drug safety profile. Most previous observational studies on the safety of DTG among pregnant women reviewed no clear evidence of increased adverse birth outcomes or congenital anomalies [28,29].
However, a study done in Botswana reported increased neural defects [20]. Most patients' data recruited have been on TDF/3TC/DTG for a period of 1year and 6months. The demographic data reviews more female access ART (366) at the facility, with 271 having suppressed viral load. This was also reported by a study on health related quality of life carried out amongst patients receiving ART in IBB specialist hospital, Minna, Niger state, Nigeria. Most patients in this facility had significant improvement despite having been on TDF/3TC/DTG for a period of three months [30]. This is remarkable as other drug combinations take about 1 year or more to achieve viral suppression as reported by Rhangales et al [31]. Also, Analissa and Colleagues reported clinical improvement and better tolerance among patients on dolutegravir-based combination when compared to others [32]. Dolutegravir-based combination is associated with weight gain [33] which seems to be desirable for HIV patients, most especially those that are stigmatized on account of weight loss and this may be one of the reasons for the noted adherence.

There were some limitations to this study. Data on viral failure amongst the paediatric patients was not retrieved, likewise the immunological recovery could not be ascertained on account of commencement of ART medications without baseline viral load and CD4 count, as requested by the donor agencies in other to reduce cost. Although a study reported that with patients on TDF/3TC/DTG, baseline viral load is not a predictor for viral suppression as adherence will bring about this [31]. Usually, these tests are done at least 6 months after the commencement of medication and some patients may not have the test carried out due to logistics reasons and sometimes, missing results. Also, this study did not compare the drugs combination that were previously dispensed unlike the study conducted in India that reviewed NVP based combination being more efficacious than Efavirenz [34]. The 
inconsistent introduction of TDF/3TC/DTG and the gradually phasing-out of other first line regimens among patients in this study hampered the interpretation of the viral and immunological results retrieved. This therefore demands for further studies to be carried out in other to address the outlined limitations.

\section{CONCLUSION AND RECOMMENDATION}

In conclusion, Dolutegravir-based fixed-dose combination therapy suppressed viral load to $<20$ copies/ml in more than $75 \%$ of patients receiving the therapy. The result of this study may be useful for policy makers, researchers and health care practitioners involved in ART care in sub Saharan Africa.

The Dolutegravir-based fixed combination has shown to have a marked clinical benefit on compliant patients with minimal manageable side effects, as such should be made readily available to patients. It also should be recommended as the first line of treatment in 'test and treat' strategy in HIV management in facilities that are yet to commence.

There is need therefore for regular review of outcome of Anti Retroviral Therapies amongst patient and strengthening of adherence programs in order to achieve viral suppression.

\section{Abbreviations}

ART: Anti retroviral therapy

HAART: Highly Active Antiretroviral

Therapy

TDF: Tenofovir

AZV: Zidovudine

3TC: Lamivudine

EFV: Efavirenz

DTG: Dolutegravir

NVP: Nevirapine

IBB: Ibrahim Badamasi Babangida

ISTI: Integrase strand transfer inhibitors

VL: Viral Load

\section{Declaration of Interest}

There was no conflict of interest

\section{Financial Support}

There was no financial support for this study.

\section{Ethical Approval}

Approval was gotten from Nnamdi Azikiwe University Teaching Hospital (NAUTH/ERB/2019/064) ethics board.

\section{Acknowledgement: None}

\section{REFERENCES}

1. World Health Organization. Dolutegravir (DTG) and the fixed dose combination (FDC) of tenofovir/lamivudine/dolutegravir (TLD). Brief note [Internet]. 2018;2:1-10. Available from: https://www.who.int/hiv/pub/arv/DTGTLD-arv_briefing_2018.pdf

2. FMOH. Rapid Advice: recommendation of Ist line antiretroviral therapy in Nigeria. Abuja; 2018.

3. WHO. Update of recommendations on firstand second-line antiretroviral regimens. 2019.

4. Indicator A, Survey I, Zone NC, Hiv H, Ministry F, Agency $\mathrm{N}$, et al. 1 naiis preliminary Findings, north central zone March 2019. 2019;(December 2018):2-5.

5. Carter AR, Biehl MH, Douwes-schultz D, Arora M. Global , regional , and national incidence, prevalence, and mortality of HIV , 1980 - 2017 , and forecasts to 2030 , for 195 countries and territories : a systematic analysis for the Global Burden of Diseases , Injuries , and Risk Factors Study 2017. 2019;(August).

6. UNAID. The 2019 Report on the global AID epidemic. In Geneva: UNAIDS; 2019.

7. Soares B, Paula A, Lins-kusterer L, Rodriguez I, Brites C. Original article Changes health-related quality of life in HIV-infected patients following initiation of antiretroviral therapy: a longitudinal study.2019;3(4):211-7.

8. Siberry G. PEPFAR support for transition to tenofovir disoproxil fumarate/lamivudine/dolutegravir (TLD). ICASA Conference,Abidjan, Cote d'Ivoire, December 2017.

9. World Health Organization. Consolidated guidelines on the use of antiretroviral drugs for treating and preventing HIV infection. Recommendations for a public health 
approach - Second edition. Available at: http://www.who.int/hiv/pub/arv/arv2016/en/. [Accessed on 22 October 2016]

10. Clinton Health Access Initiative. ARV Market Report. Available at: https:/clintonhealthaccess.org/content/uploa ds/2017/09/2017-ARV-Market-

Report_Final-2.pdf. [Accessed on 6 December 2017]

11. Clotet B, Feinberg J, Lunzen JV, KhuongJosses MA, Antinori A, Dumitru I. et al. Once-daily dolutegravir versus darunavir plus ritonavir in antiretroviral-naive adults with HIV-1 infection (FLAMINGO): 48 week results from the randomised openlabel phase 3b study. Lancet. 2014;383 (9936):2222-2231.

12. Bollen P, Reiss P, Schapiro J, Burger D. Clinical pharmacokinetics and pharmacodynamics of dolutegravir used as a single tablet regimen for the treatment of HIV-1 infection. Expert Opin Drug Saf. 2015;14(9):1457-1472

13. Malet I, Thierry E, Wirden M, Lebourgeois S, Subra F, Katlama C. et al. Combination of two pathways involved in raltegravir resistance confers dolutegravir resistance. $J$ Antimicrob Chemother. 2015;70(10):28702880.

14. Liang J, Mesplède T, Oliveira M, Anstett K, Wainberg MA. The combination of the R263K and T66I resistance substitutions in HIV-1 integrase is incompatible with highlevel viral replication and the development of high-level drug resistance. $J$ Virol. 2015;89(22):11269-11274.

15. Pham HT, Mesplède $T$, Wainberg MA. Effect on HIV-1 viral replication capacity of DTG-resistance mutations in NRTI/ NNRTI resistant viruses. Retrovirology. 2016;13(1): 31.

16. Chou TC. Derivation and properties of Michaelis-Menten type and Hill type equations for reference ligands. $J$ Theor Biol. 1976;59(2):253-276.

17. Shen L, Peterson S, Sedaghat AR, McMahon MA, Callender M, Zhang $\mathrm{H}$. et al. Dose-response curve slope sets classspecific limits on inhibitory potential of anti-HIV drugs. Nat Med. 2008;14(7):762766.

18. Rhee SY, Gonzales MJ, Kantor R, Betts BJ, Ravela J, Shafer RW. Human immunodeficiency virus reverse transcriptase and protease sequence database. Nucleic Acids Res. 2003;31(1):298-303.

19. Shafer RW. Rationale and uses of a public HIV drug-resistance database. J Infect Dis. 2006;194 Suppl 1:S51-S58.

20. Zash R, Makhema J, Shapiro RL. Neuraltube defects with dolutegravir treatment from the time of conception. $N$ Engl $J$ Med 2018; 379: 979-81.

21. Department of Health Services and Government of Nepal, Nepal Surveillance Guidelines: Annex on the National Strategy for Surveillance of HIV Drug Resistance, Department of Health Services, Government of Nepal, Kathmandu, Nepal, 2011.

22. Ojha C R, Geeta S,Dumre S P.Virological and Immunological Status of People Living with HIV/AIDS undergoing ART treatment in Nepal. Biomedical Research International.2016;Article ID 6817325:7 http:dx.doi.org/10..1155/2016/68117325

23. UNAIDS. Nigeria National HIV/AIDs Indicator and Impact Survey(NAIS). Available at https: //www.unaids.org. Accessed on 12th February, 2021

24. O. M. Radchuk,N. P. Chentsova, and S.V. Tukaiev, "Outcome of antiretroviral treatment in patients with AIDS monoinfection and those co-infected with hepatitis B and C viruses and tuberculosis in Ukraine," Central European Journal of Public Health, vol. 22, no. 3, pp. 143-146, 2014.

25. J. Wang, C.He, J. H. His, Leng X, Liang S, Ma Y, Dong Y. et al., "Virological outcomes and drug resistance in Chinese patients after 12 months of 3TC-based firstline antiretroviral treatment, 2011-2012," PLoS ONE, vol. 9, no. 2, Article ID e88305, 2014.

26. J. Silva, K. Pereira, J. Rijo, Dumbre SP. et al., "A retrospective observational study of low-level viraemia and its immunological and virological significance: which outcome to expect," Journal of the International AIDS Society, vol. 17, no. 4, supplement 3, Article ID 19668, 2014.

27. N. Khienprasit, R. Chaiwarith, T. Sirisanthana, and K. Supparatpinyo, "Incidence and risk factors of antiretroviral treatment failure in treatment-na"ive HIVinfected patients at ChiangMai University Hospital, Thailand," AIDS Research and Therapy, vol. 8, article 42, 2011. 
28. More research is needed on the use of TAF in pregnant women and people with HIV_TB coinfection taking RIF-based treatment to justify widespread use of the new TAF/3TC/DTG combination in LMICs.

29. Zash R, Jacobson D, Mayondi G, Diseko M, Makhema J, Mmalane M, et al. Dolutegravir /tenofovir /emtricitabine (DTG/TDF/FTC) started in pregnancy is as safe as efavirenz /tenofovir /emtricitabine (EFV/TDF/FTC) in nationwide birth outcomes surveillance in Botswana. International AIDS Society Conference; Paris, France 2017.

30. Umar D, Waziri B, Ndagi U, Mohammed H A. Impact of Tenofovir/Lamivudine/Dolutegravir(TLD) on the Health- related quality of life and the clinical outcomes of HIV/AIDs patients at a Tertiary health Facility in Niger state. DOI. https:// doi.org110.21203/rs.3.rs-127273/j/

31. Rahangdale L, Cates J, Potter J, Badell M, Siedman D, Miller E. et all Integrase inhibitors in late pregnancy and rapid HIV viral load reduction. Am J Obstet Gynaecol. 2016;1-7.
32. Mondi A, Cozzi-lepri A, Tavelli A, Rusconi S, Vichi F, Ceccherini-silberstein F, et al. Effectiveness of dolutegravir-based regimens as either first-line or switch antiretroviral therapy : data from the Icona cohort. 2019;(July 2018):1-10.

33. Kumar S, Samaras K. The Impact of Weight Gain During HIV Treatment on Risk of Prediabetes, Diabetes Mellitus, Cardiovascular Disease, and Mortality. 2018;9(November): 1-14.

34. Sinha S, Raghunandan P, Chandrashekhar R, Sharma S, Kumar S, Dhooria S. et al., "Nevirapine versus efavirenz-based antiretroviral therapy regimens in antiretroviral-naive patients with HIV and tuberculosis infections in India: a pilot study," BMC Infectious Diseases. 2013; Vol. 13, article 482.

How to cite this article: Ogbuagu CN, Ogbuagu EN, Okoh EE et.al. Outcome of fixed dose combination of tenofovir, lamivudine and dolutegravir in rural HIV care facility in Nigeria. Int J Health Sci Res. 2021; 11(12):1-8. DOI: https://doi.org/10.52403/ijhsr.20211201 